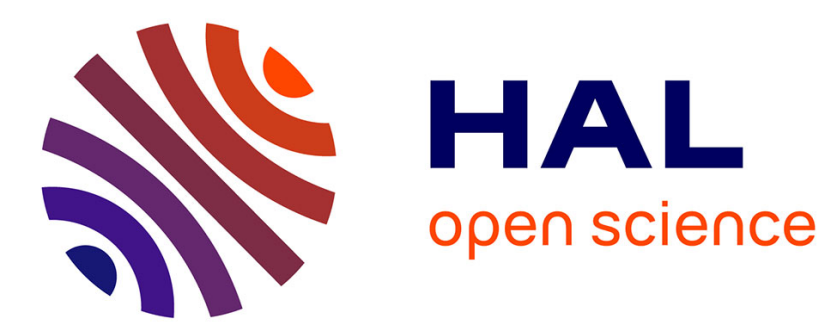

\title{
Genetic isolation between two recently diverged populations of a symbiotic fungus
}

\author{
Sara Branco, Pierre P. Gladieux, Christopher Ellison, Alan Kuo, Kurt \\ Labutti, Anna Lipzen, Igor V I. V. Grigoriev, Liao Hui-Ling, Rytas Vilgalys, \\ Kabir G. Peay, et al.
}

\section{To cite this version:}

Sara Branco, Pierre P. Gladieux, Christopher Ellison, Alan Kuo, Kurt Labutti, et al.. Genetic isolation between two recently diverged populations of a symbiotic fungus. Molecular Ecology, 2015, 24 (11), pp.2747-2758. 10.1111/mec.13132 . hal-01303143

\section{HAL Id: hal-01303143 \\ https://hal.science/hal-01303143}

Submitted on 11 May 2016

HAL is a multi-disciplinary open access archive for the deposit and dissemination of scientific research documents, whether they are published or not. The documents may come from teaching and research institutions in France or abroad, or from public or private research centers.
L'archive ouverte pluridisciplinaire HAL, est destinée au dépôt et à la diffusion de documents scientifiques de niveau recherche, publiés ou non, émanant des établissements d'enseignement et de recherche français ou étrangers, des laboratoires publics ou privés. 


\section{MOLECULAR ECOLOGY}

\section{Genetic isolation between two recently diverged populations of a symbiotic fungus}

\begin{tabular}{|r|l|}
\hline Journal: & Molecular Ecology \\
\hline Manuscript ID: & Draft \\
\hline Manuscript Type: & Original Article \\
\hline Date Submitted by the Author: & n/a \\
\hline Complete List of Authors: & \begin{tabular}{rl|} 
Branco, Sara; University of California, Berkeley, Plant and Microbial Biology \\
Gladieux, Pierre; University Paris Sud, Laboratoire d'Ecologie, \\
Systematique et Evolution \\
Ellison, Chris; University of California, Berkeley, Integrative Biology \\
Kuo, Allan; Department of Energy, Joint Genome Institute \\
LaButii, Kurt; Department of Energy, Joint Genome Institute \\
Lipzen, Anna; Department of Energy, Joint Genome Institute \\
Grigoriev, Igor; Department of Energy, Joint Genome Institute \\
Liao, Hui-Ling; Duke University, Biology \\
Vilgalys, Rytas; Duke University, Biology \\
Peay, Kabir; Stanford University, Biology \\
Taylor, John; University of California, Berkeley, Plant and Microbial Biology \\
Bruns, Thomas; University of California Berkeley, Plant and Microbial \\
Biology; University of California, Berkeley, Plant and Microbial Biology
\end{tabular} \\
\hline Keywords: & $\begin{array}{l}\text { Adaptation, Fungi, Natural Selection and Contemporary Evolution, } \\
\text { Population Genetics - Empirical }\end{array}$ \\
\hline
\end{tabular}


1 Genetic isolation between two recently diverged populations of a symbiotic fungus

2 Sara Branco ${ }^{1}$, Pierre Gladieux ${ }^{2}$, Christopher E. Ellison ${ }^{3}$, Alan $\mathrm{Kuo}^{4}$, Kurt LaButii ${ }^{4}$, Anna

3 Lipzen $^{4}$, Igor V. Grigoriev ${ }^{4}$, Hui-Ling Liao ${ }^{5}$, Rytas Vilgalys ${ }^{5}$, Kabir G. Peay ${ }^{6}$, John W.

4 Taylor $^{1}$, Thomas D. Bruns ${ }^{1}$

5

$6{ }^{1}$ Department of Plant and Microbial Biology, University of California, Berkeley,

7 California, United States of America

$8{ }^{2}$ Laboratoire d'Ecologie, Systematique et Evolution, Universite Paris Sud, Orsay, France

$9{ }^{3}$ Department of Integrative Biology, University of California, Berkeley, California,

10 United States of America

$11{ }^{4}$ Department of Energy, Joint Genome Institute, Walnut Creek, California, United States

12 of America

$13{ }^{5}$ Department of Biology, Duke University, Durham, North Carolina, United States of

14 America

$15{ }^{6}$ Department of Biology, Stanford University, Stanford, California, United States of

16 America

18 Keywords - Adaptation; population genomics; mycorrhizal fungi; Suillus brevipes

19

20 Corresponding author - Sara Branco; sara.mayer.branco@gmail.com

22 Running title - Recent fungal population divergence 


\section{Genetic isolation between two recently diverged populations of a symbiotic fungus}

25 Sara Branco, Pierre Gladieux, Christopher E. Ellison, Alan Kuo, Kurt LaButii, Anna

26 Lipzen, Igor V. Grigoriev, Hui-Ling Liao, Rytas Vilgalys, Kabir G. Peay, John W.

27 Taylor, Thomas D. Bruns

29 Abstract

30 Fungi are an omnipresent and highly diverse group of organisms, making up a

31 significant part of eukaryotic diversity. Little is currently known about the drivers of

32 fungal population differentiation and subsequent divergence of species, particularly in

33 symbiotic fungi. Here we investigate the population structure and environmental

34 adaptation in Suillus brevipes (Peck) Kuntze, a wind-dispersed soil fungus that is

35 symbiotic with pine trees. We assembled and annotated the reference genome for $S$.

36 brevipes and re-sequenced the whole genomes of 28 individuals from coastal and

37 montane sites in California. We detected two highly supported populations with very low

38 divergence and no evidence for migration. However, we detected highly differentiated

39 genomic regions, most notably a region that contains a gene encoding for a membrane

$40 \mathrm{Na}^{+} / \mathrm{H}^{+}$exchanger known for enhancing salt tolerance in plants and yeast. Our results are

41 consistent with a very recent split between the montane and coastal S. brevipes

42 populations, with few small genomic regions under positive selection and a pattern of

43 dispersal and/or establishment limitation. This is the first population genomics study

44 comprising a member of the phylum Basidiomycota or of a mycorrhizal fungus. It

45 documents the least differentiated fungal populations currently known and identifies a 
46 putatively adaptive gene that motivates further functional tests to link genotypes and

47 phenotypes and shed light on the genetic basis of adaptive traits.

\section{Introduction}

The way organisms are distributed across the landscape is the result of their

51 ability to reach, establish and persist in suitable habitats. Factors such as dispersal and

52 establishment limitation influence these abilities, shaping the genetic diversity of

53 populations in nature. Fungi are no exception. They have simple morphologies allied to

54 well-defined ecological niches, comprise considerable diversity and tend to have small

55 genomes. These features make them good models for studying population differentiation

56 and adaptation in nature (Gladieux et al., 2014). Unlike most animals and plants, the vast

57 majority of fungi produce copious amounts of microscopic airborne propagules and are

58 often assumed to have exceptional long-range dispersal capabilities (Brown et al., 2013)

59 leading to wide distributions and large population sizes (Green \& Bohannan, 2006). This

60 idea has however been recently challenged by ecological evidence that dispersal

61 limitation at the landscape scale affects community structure and richness (Peay et al.,

62 2012) and that there is widespread fungal regional endemism (Taylor et al., 2006,

63 Amend et al., 2010, Talbot et al., 2014). Even though fungi are good models for

64 understanding the genetic basis of evolutionary change, it is not yet clear how fungal

65 adaptive divergence occurs and whether it is linked to dispersal, natural selection, or

66 both.

Environmental factors are known to drive fungal adaptation, with temperature as a

68 recurrent feature associated with wild fungal population differentiation even in host- 
69 associated fungi (Vacher et al., 2008, Frenkel et al., 2010, Ellison et al., 2011, Mboup et

70 al., 2012). However, fungal population genomics and adaptation have been studied in a

71 very small set of fungi (Liti et al., 2009, Neafsey et al., 2010, Ellison et al., 2011,

72 Rosenblum et al., 2013). This limited sample leaves out an immense diversity of fungal

73 groups and life histories, including all symbiotic basidiomycete mushroom-forming

74 fungi. The phylum Basidiomycota is one of the largest fungal phyla, comprising about

7530,000 species (James et al., 2006) and including the majority of mycorrhizal species,

76 which are soil fungi living in obligate symbiotic associations with vascular plants (Smith

77 \& Read, 2010). In particular, ectomycorrhizal (EM) fungi are an important group

78 associated with a wide range of plant families including tree species dominant in many

79 biomes. EM fungi play a crucial role in forest ecosystems by providing water and

80 nutrients to their host trees, for which they receive carbohydrates in return (Smith \&

81 Read, 2010). Although there have been attempts to understand EM fungal population

82 genetics (Douhan et al., 2011), little is currently known about the patterns of population

83 structure in these fungi or on the relative role of dispersal limitation and local adaptation

84 in shaping fungal diversity.

85 Here we report on the first population genomics study of an EM basidiomycete

86 fungus. We compile a new fungal reference genome, document fungal population

87 structure and investigate candidate genomic regions for local adaptation. We focused on

88 Suillus brevipes, a widespread North American EM fungus associated with pine trees

89 (Smith \& Thiers, 1964). S. brevipes is a soil fungus and reproduces by forming fruiting

90 bodies that produce and disperse in the order of $10^{8}$ airborne spores per mushroom

91 (Dahlberg \& Stenlid, 1994). It plays an important ecological role as a pioneer species, 
92 colonizing pine seedlings and young trees (Peay et al., 2012) and contrary to most EM

93 species, is amenable for in vitro cultures, making it possible to document population

94 differentiation and to unveil its causal mechanisms. We assembled and annotated the $S$.

95 brevipes reference genome and re-sequenced the genomes of isolates collected from two

96 contrasting environments in California, coastal mixed Pinus muricata and P. contorta

97 and mountain $P$. contorta forests separated by $300 \mathrm{~km}$ of inhospitable habitat, lacking

98 either plant host. Given the inherent differences between coastal and montane

99 environments, we expected to find clearly differentiated and locally adapted populations,

100 with strong signatures of positive selection in genomic regions related to factors known

101 to be relevant for fungal ecology and evolution, such as host tree, climate, and/or soil

102 type. We also hypothesized ongoing gene flow between the coast and mountains,

103 facilitated by the massive amounts of airborne spores produced by $S$. brevipes.

104 Surprisingly, we detected distinct yet very little diverged coastal and montane

105 populations, with only 155 reciprocally fixed SNPs. Demographic modeling pointed to

106 isolation as the most likely model, with the absence of gene flow between the two

107 populations. We also identified a small set of highly differentiated genomic regions,

108 including a gene involved in salt tolerance, indicating positive selection plays a role in

109 shaping these populations and suggesting the emergence of local adaptation in $S$.

110 brevipes.

111

112 Materials and Methods

113 Isolate collection, culturing, and DNA extraction and sequencing 
114 Suillus brevipes (Peck) Kuntze individual sporocarps were collected from pine

115 forests from the coast and mountains of Northern California (Table S1). We harvested 11

116 coastal individuals in Mendocino County, Salt Point and Point Reyes National Seashore

117 from forests dominated by Pinus muricata with residual P. contorta in the Mendocino

118 site (under the Scientific Research and Collecting Permit \# PORE-2011-SCI-0014).

119 These sites are characterized by a Mediterranean climate with cool summers and mild

120 winters with temperatures rarely reaching below freezing. We also collected $17 S$.

121 brevipes individuals in the Sierra Nevada mountains (Yosemite National Park; under the

122 Scientific Research and Collecting Permit \# YOSE-2013-SCI-0071) from P. contorta

123 forests, around $300 \mathrm{~km}$ East from the coastal sites. These mountains also offer a

124 Mediterranean climate but winters include below freezing temperatures and most

125 precipitation arrives as snowfall. Sporocarps were collected at least 10 meters apart to

126 ensure selection of different genets (Bergemann \& Miller, 2002, Dahlberg \& Stenlid,

127 1994), with some mountain individuals separated by up to 30 miles and coastal

128 individuals separated by over 50 miles. The coastal and mountain collection sites are

129 separated by dry, non-forested and inhospitable Californian Central Valley habitat.

130 We obtained pure cultures from each individual by placing a piece of each sporocarp

131 in full strength Modified Melin-Norkrans (MMN) agar plates. Pure mycelium was

132 harvested after no more than two weeks of growth, flash frozen in liquid N, and stored at

133 -80C. Genomic DNA was obtained for each isolate using a CTAB-based extraction

134 protocol. Genomic libraries were generated with Apollo 324 NGS Library Prep System

135 (Wafergen Biosystems) and samples were sequenced in 3 lanes of Illumina HiSeq2000,

136 100bp paired-end with a 350bp insert size at the QB3 Vincent J. Coates Genomics 
137 Sequencing Laboratory at the University of California, Berkeley. The raw reads were

138 deposited in the Short Read Archive and the accession numbers are listed in Table S1.

139 One mountain isolate ( $\mathrm{Sb} 2)$ was selected as the reference genome and deposited in the

140 CBS Collection of Fungi, with accession number CBS 139023. DNA was extracted as

141 above, however library preparation, sequencing, genome assembly and annotation were

142 carried out by the US DOE Joint Genome Institute under the 1000 Fungal Genomes

143 project (Grigoriev et al., 2013). The genome was sequenced using Illumina HiSeq

144 platform. Paired-end reads from 270bp insert size standard Illumina library were filtered

145 for artifact/process contamination and subsequently assembled as a diploid using

146 AllPathsLG release version R43839 (Gnerre et al., 2011). The final assembly of 1550

147 scaffolds has an N50 of $159 \mathrm{kbp}$ and an L50 of 83. The assembly was repeat-masked and

148 annotated using the JGI Annotation Pipeline (Kuo et al., 2014). Briefly, the Pipeline

149 computes multiple gene models at each locus using a variety of RNASeq-based, protein-

150 based, and ab initio gene predictors, characterizes those models by predicting functional

151 domains and signal peptides, and selects the highest quality model at each locus based on

152 expression, similarity to known proteins, and domain content. In addition, the Pipeline

153 compares the draft gene set to those of other genomes and builds a draft set of gene

154 families. Finally, the Pipeline exports the assembly and annotation to an interactive Portal

155 in MycoCosm (Grigoriev et al., 2013). The Suillus brevipes Sb2 Portal can be found at

156 http://genome.jgi.doe.gov/Suillus_brevipes/

157

158 Read filtering, mapping and variant calling 
159 Isolate re-sequencing produced over 60 million sequences. Reads were filtered based

160 on quality and all duplicates and reads with more than $10 \%$ Ns, and with at least one base

161 with phred score smaller than 20 were discarded. Read pairs were re-grouped and orphan

162 reads were also discarded. All good quality paired reads were then aligned to the

163 reference genome using Bowtie2. 2.1.0 (Langmead \& Salzberg, 2012). Alignments were

164 sorted with SAMtools (Li et al., 2009) and duplicate and poor quality alignments

165 removed with Picard (http://picard.sourceforge.net) and BamTools (Barnett et al., 2011).

166 Realignment, indexing and SNP calling was performed with the Genome Analyses

167 Toolkit (GATK; McKenna et al., 2010), using unified genotyper. We discarded

168 singletons, poor quality SNPs $(<30)$ and SNPs including Ns using VCFtools (Danecek et

$169 a l ., 2011)$ and in-house scripts. Per individual genome coverage was calculated using

170 GATK.

171

Population structure

173 Population structure was inferred using both clustering and phylogenetic inference.

174 We used 567192 SNPs (excluding singletons) to compute a neighbor-joining tree with

175 PHYLIP (Felsenstein, 2002) including all the $S$. brevipes isolates. We also used FRAPPE

176 to compute global ancestry from maximum likelihood estimates of model parameters

177 (Tang et al., 2005) and assess population structure. Two coastal isolates, Sb7 and Sb10,

178 were collected just 10m apart in Mendocino. These individuals shared 97\% SNPs, so we

179 considered them to be clones and removed $\mathrm{Sb} 7$ from further analyses.

$181 \quad$ Polymorphism and genome scans for divergence 
182 Gene and genome wide polymorphism were assessed using egglib (Mita \& Siol, 183 2012) and in-house scripts. We calculated the average 5kb window and gene number of 184 segregating sites and the whole genome and genic nucleotide diversity $(\pi)$, including 185 silent and non-silent $\pi$ in each population. We also calculated Tajima's D to test for 186 neutrality and Zeng's E to compare for high- and low-frequency variants (Zeng et al.,

187 2006). In addition, we calculated the average number of nucleotide substitutions per site

188 between populations (Dxy) for $5 \mathrm{~Kb}$ windows and measured population differentiation

189 due to genetic structure by computing the average genome-wide Weir Cockerham's Fst

190 and average Fst per 5Kb and $1 \mathrm{~Kb}$ windows with VCFtools (Danecek et al., 2011). We

191 calculated fixed and exclusive differences as well as expected and observed

192 heterozygocity across the two populations with in-house scripts.

194 Demography

195 Population demography was analyzed using a diffusion-based approach implemented

196 in the program $\partial \mathrm{a} \partial \mathrm{i}$ (Gutenkunst et al., 2009). Demographic parameters were estimated

197 from the joint mountain and coastal S. brevipes allele frequency spectra polarized with

198 the $S$. luteus genome sequence. Given the risk for potential misidentification of ancestral

199 states, we also fitted the model using folded allele frequency spectra. Conventional

200 bootstrapping (100 replicates) was calculated to estimate parameter uncertainties. 201

202 Natural selection 
204 within each population, performed McDonald Kreitman tests and computed a selective

205 sweep analysis. We selected the top $1 \%$ Dxy values for $5 \mathrm{~Kb}$ windows and top $0.1 \%$ Fst

206 values for $5 \mathrm{~Kb}$ and $1 \mathrm{~Kb}$ windows to search for differentiated regions across the two

207 populations and respective genes. The functions of these highly differentiated genes were

208 inferred by retrieving gene ontology categories from MycoCosm (Grigoriev et al., 2013).

209 We also identified genes showing and excess of amino acid substitutions using the

210 MacDonald-Kreitman test (McDonald \& Kreitman, 1991), with S. luteus as the outgroup.

211 We filtered the results to exclude genes that showed limited variability and corrected for

212 multiple hypothesis testing using the Benjamini-Hochberg method (Benjamini \&

213 Hochberg, 1995).

214 We searched for selective sweeps by measuring haplotype homozygosity using an in-

215 house script (Wilson \& Messer, unpublished). This program calculates an $\mathrm{H}$ statistics to

216 detect hard and soft sweeps by measuring the length of pairwise homozygocity stretches

217 in a population sample generated by elevated linkage disequilibrium around adaptive

218 sites.

$220 \quad$ Results

$221 \quad$ Suillus brevipes genomes

222 The S. brevipes reference genome (obtained from Sb2, a mountain individual

223 included in this study) was assembled into 1550 scaffolds totaling $51.7 \mathrm{Mbp}$ and

224 annotated. The 22,453 predicted genes, represent 2313 distinct protein domains, and 
225 cluster into 2844 multigene families. Details on the genome assembly and annotation can 226 be found in Table S2.

227 The average sequence coverage per individual varied from $7 \mathrm{X}$ to $26 \mathrm{X}$ (Table S1).

228 We recovered a total of 1254275 single nucleotide polymorphisms (SNPs) across the 28

229 S. brevipes genomes, with $2.4 \%$ of the genome as variable sites.

\section{Population subdivision}

232 Using a neighbor-joining approach we found two distinct and highly supported

233 Suillus brevipes montane and coastal populations (Fig. 1a). The same two populations

234 were found with a maximum likelihood population structure analysis using FRAPPE,

235 which emphasized the shared ancestry of the two populations (Fig. 1b). All individuals

236 collected from montane Yosemite National Park clustered together, and individuals from

237 coastal Mendocino, Point Reyes, and Salt Point formed another cluster with no evidence 238 of geographic substructure.

$240 \quad$ Genomic diversity, differentiation and divergence

241 Genomic summary statistics were estimated using 5kb sliding windows (6387

242 windows for the mountain population and 6301 for the coast population) and the genic

243 regions (22453 genes) (Table 1). The two populations presented comparable levels of

244 genetic variation, and each population showed close to $2 \%$ polymorphism across the

245 genome and $0.2 \%$ in the genic regions. The average observed heterozygosity was similar

246 in both populations $\left(\mathrm{Ho}_{\text {Coast }}=0.32 \pm 0.19, \mathrm{Ho}_{\text {Mountain }}=0.28 \pm 0.18\right)$, and only slightly

247 higher than the heterozygosity expected under Hardy Weinberg equilibrium $\left(\mathrm{He}_{\mathrm{Coast}}=\right.$ 
$\left.248 \quad 0.20 \pm 0.21 ; \mathrm{He}_{\text {Mountain }}=0.21 \pm 0.21\right)$. Nucleotide diversity $(\pi)$ was also similar between

249 coast and mountain (Table 1). Tajima's D was slightly negative, indicating a genome-

250 wide excess of low frequency polymorphism compared to neutral expectations, however

251 this was not observed when including only genic regions (Table 1). Zeng's E statistics,

252 which measures positive selection, was negative in both coastal and montane populations,

253 indicating an excess of high frequency derived polymorphisms in both populations. In

254 fact, testing the fit between the observed site frequency spectra and spectra generated

255 with a constant size model using the PYTHON package $\partial \mathrm{a} \partial \mathrm{i}$ (Gutenkunst et al., 2009)

256 detected departures from the standard neutral model in both populations (mountain

257 chisquare, d.f. $=32, P=0$; coast chisquare, d.f. $=20, P=0$ ).

$258 \quad$ Most of the SNPs were shared between the two populations (44\%) and only 155

$259(0.01 \%)$ of the sites were reciprocally fixed for different alleles in the two populations.

260 The remaining SNPs were variable in one population and fixed in the other (Table 2).

261 This distribution of polymorphism and divergence suggests a recent split between the two

262 populations, the prevalence of gene flow, or both. The mean pairwise nucleotide

263 difference between populations (Dxy) for $5 \mathrm{~kb}$ windows was 0.008 , consistent with the

264 results of the clustering analyses.

265

266 Demography

267 Demographic inference of coastal and montane populations indicated isolation

268 (absence of gene flow) between the mountain and coastal populations as the most likely

269 demographic model (Table 3). Inference using folded site frequency spectra also pointed

270 to the isolation model as the best fit to the data (isolation likelihood $=-32595.1$; 
271 migration likelihood $=-239130.9)$, suggesting that model choice was not biased by

272 multiple mutations along the outgroup branch.

273 The maximum-likelihood parameter estimates for the unfolded isolation model are

274 reported in Table 4. The coastal population is estimated to have a smaller effective

275 population size compared to the montane population and the estimated divergence time is

27625000 generations. Even though this is the most likely of all tested demographic models,

277 the unfolded modeled site frequency spectrum did not fit the observed data well

278 (chisquare test mountain: d.f. $=33, P=0$; chisquare test coast: d.f. $=21, P=0$ ). The poor

279 fit was due to a deficit of high frequency derived alleles in simulated site frequency

280 spectra compared to the observed dataset (Fig S1).

281

282

Genome scans for natural selection

283 In order to test for natural selection, we investigated genomic regions with a high

284 proportion of reciprocally fixed SNPs, regions identified as outliers for Dxy and Fst

285 (Noor \& Bennett, 2009, Cruickshank \& Hahn, 2014). We also used McDonald-Kreitman

286 tests and selective sweep analysis to identify signals of positive selection across the

287 genome.

288 Out of the detected 155 reciprocally fixed differences, 30 were in genic regions.

289 Scaffold 16 hosted $30 \%$ of these, with 5 non-synonymous fixed differences, and scaffold

29012 included 20\%, of which 4 were non-synonymous. Three of these genes had known

291 functions. Scaffold 16 includes gene 669775, which codes for a protein kinase. Scaffold

29212 includes three adjacent genes with six fixed differences. 826957 has no known

293 function, 826959 codes for a cysteine-type endopeptidase and 826958 is involved in $\mathrm{pH}$ 
294 regulation. The latter is invariable in the coastal individuals (Fig. 2) and codes for a

$295 \mathrm{Na}^{+} / \mathrm{H}^{+}$exchanger, which is a membrane protein involved in salt tolerance in

296 Sacchromyces cerevisiae and Arabidopsis (Nass et al., 1997, Apse et al., 1999). The $S$.

297 cerevisiae homolog Nhal encodes for a membrane protein involved in $\mathrm{Na}^{+}$and $\mathrm{K}^{+}$efflux

298 needed for yeast to tolerate alkali cation tolerance at acidic pH (Bañuelos et al., 1998).

299 Gene 826958 will hereafter be referred to as Nhal-like.

300 We used Dxy outliers as an absolute divergence metric to scan the genome for

301 regions under divergent selection (Noor \& Bennett, 2009, Cruickshank \& Hahn, 2014).

302 Table S3 reports the genes located in the top $1 \% 5 \mathrm{~kb}$ window Dxy values. These encode

303 proteins with a wide variety of functions, with $20 \%$ involved in transporter activity.

304 Nhal-like and flanking genes in scaffold 12 (coding for an endopeptidase and another

305 unknown protein) were included in the Dxy outlier list.

306 We also investigated Fst across the genome. On average Fst values per SNP were

307 low (average Fst $=0.053$, s.d. $=0.115)$, as expected given the low level of differentiation

308 between populations. Fst was also calculated for $5 \mathrm{~Kb}$ and $1 \mathrm{~Kb}$ genomic sliding windows

309 and compared to the list of Dxy outliers. The majority of windows showed low Fst values

310 yet some regions had high relative divergence. Fig. 3 depicts the $1 \mathrm{~Kb}$ window Fst values,

311 showing 807 windows displaying Fst values above 0.5 . We found 24 genes associated

312 with the top $0.1 \%$ of $1 \mathrm{~kb}$ windows with highest Fst values (Table 5). These are involved

313 in a variety of cellular functions, namely transporter, catalytic, oxidoreductase activities

314 and DNA binding. Four Dxy outliers were also on this list, including one gene in scaffold

31566 and the three Dxy outlier genes in scaffold 12 (these were not listed as Fst outliers 
316 when scanning the genomes with $5 \mathrm{~Kb}$ windows). Gene Nhal-like fell in the window with

317 the maximum Fst value $(\mathrm{Fst}=1)$.

318 Using McDonald Kreitman tests, we found four genes displaying significant

319 differences between ratios of non-synonymous to synonymous substitutions within and

320 between species, which are consistent with positive selection (Table S4). These are

321 involved in heterokaryon incompatibility (also listed as a Dxy outlier), carbohydrate

322 metabolic processes, and post-translational processes in organelles.

323 We did not find signals of recent selective sweeps across the genome. We quantified

324 haplotype homozygosity using an $\mathrm{H}$ statistics that measures the length of pairwise

325 homozygocity stretches in a population sample generated by elevated linkage

326 disequilibrium around adaptive sites (Wilson and Messer, unpublished). The highest $\mathrm{H}$

327 values are listed in Table S5 and show no evidence for selective sweeps.

\section{Discussion}

330 Our study revealed emerging differentiation of Suillus brevipes populations in two

331 contrasting environments at a relatively small spatial scale. We found a very recent split

332 between montane and coastal populations in California with no evidence for post-

333 divergence migration, as indicated by low population divergence, the presence of very

334 few reciprocally fixed differences and genetic isolation as the most likely demographic

335 model. Despite the low overall genomic divergence, we detected a small set of highly

336 differentiated and positively selected genes across the two populations. These results are

337 consistent with the early stages of environmental adaptation. 
338 Our results point to the existence of dispersal and/or colonization limitation in Suilus

339 brevipes, which can result from constraints in physically moving spores or challenges in

340 spore germination and mycelium persistence in new habitats. Although Suillus is known

341 to be a prolific disperser, producing annual spore loads on the order of trillions of spores

342 per $\mathrm{km}^{2}$, spore loads decrease exponentially with distance from their source, rendering

343 colonization of new host trees and establishment in new habitats less effective than

344 expected (Peay et al., 2012). This finding makes spore dispersal limitation a good

345 candidate explanation for the lack of gene flow between coastal and montane populations

346 in California. These habitats are separated by the Central Valley, which comprises an

347 approximate $300 \mathrm{~km}$ non-forested gap that based on our results appears to represent an

348 effective geographic barrier to migration between the coastal and montane populations of

349 S. brevipes.

350 Despite demographic modeling pointing to two allopatric S. brevipes populations as

351 the most likely demographic model, this model had a poor fit to the data due to an excess

352 of high frequency derived alleles in both populations (Fig. S1). This pattern could be an

353 artifact derived from misidentification of ancestral alleles or a true biological pattern,

354 explained by more complex demographic scenarios (including bottlenecks) or genome-

355 wide positive selection, such as selective sweeps (Ellison et al., 2011, Caicedo et al.,

356 2007). We had access to a single outgroup (S. luteus, the sister species to S. brevipes),

357 making it challenging to control for errors in calling ancestral alleles. However, results

358 from demographic modeling without an outgroup (using a folded site frequency spectra)

359 also pointed to absence of migration as the most probable scenario. Furthermore, we 
360 failed to detect selective sweeps indicating genome-wide positive selection is probably

361 not the cause for the non-monotonic observed site frequency spectra.

362 The few available studies investigating wild EM fungal population structure report

363 mixed trends, ranging from panmixis to strong population differentiation (Douhan et al.,

364 2011). Microsatellite approaches conducted in several EM fungal species point to

365 examples of lack of population structure, extensive gene flow and little genetic

366 differentiation both at local and regional spatial scales (Zhou et al., 2001, Kretzer et al.,

367 2005, Bergemann et al., 2006, Muller et al., 2007, Roy et al., 2008, Rivera et al., 2014).

368 However, most of these studies were based on a very small number of markers that might

369 have been insufficient to detect emerging population differentiation. In fact, several other

370 examples point to high levels of population differentiation in EM fungi (Bergemann \&

371 Miller, 2002, Grubisha et al., 2007, Carriconde et al., 2008, Amend et al., 2010, Dunham

372 et al., 2013). In this regard, population genomics of the saprobe Neurospora, detected

373 structure hidden in microsatellite analysis (Ellison et al., 2011). Unfortunately, the causes

374 underlying population differentiation are not always clear.

375 The few highly differentiated genomic regions are consistent with the very early

376 steps in local adaptation in Suillus brevipes. In particular, the reduced nucleotide diversity

377 among coastal individuals at the Nhal-like gene is consistent with recent positive

378 selection in the coastal population, making it tempting to hypothesize that the coastal

379 allele of this gene spread by natural selection for adaptation to the stress of saline soil.

380 Consistent with this hypothesis, soil analyses from at least the Point Reyes area confirm

381 high Na content, with an average of $170 \mathrm{ppm}$, and acidic $\mathrm{pH}$ (average $\mathrm{pH}=5.1$; Peay et

382 al., 2010). Basidiomycetes are in general relatively salt-intolerant and saline soils are 
383 known to host poorly diverse EM fungal communities (Schechter \& Branco, 2014 and

384 references therein). Further research will be needed to fully understand the role of gene

385 Nhal-like for salt tolerance in Suillus brevipes.

386 Our study is one of the few available fungal population genomic studies so far and

387 provides the earliest example of divergence and emergence of environmentally adapted

388 fungal populations. Other studies also reported evidence of adaptive evolution, revealing

389 more complex patterns of genomic differentiation, demographics and positive selection.

390 A pioneer population genomics study on wild and domesticated yeasts (Saccharomyces

391 cerevisiae and S. paradoxus) found worldwide population differentiation correlated to

392 phenotypic variation (Liti et al., 2009). Ellison et al., 2011 found evidence of cryptic

393 population differentiation and local adaptation in Neurospora crassa. Their genome scans

394 revealed distinct populations at different latitudes, with up to $9 \%$ genomic divergence,

395 asymmetrical migration and areas of genomic differentiation including genes related to

396 temperature and circadian rhythm, showing environmental factors shape fungal

397 evolution. Batrachochytrium dendrobatidis, the amphibian-killing chytrid fungus, was

398 found to include high genetic variation across populations and a complex evolutionary

399 history, including differences in chromosome copy numbers and heterozygosity across

400 isolates as well as signatures of selection in genes involved in amphibian skin infection

401 (Rosenblum et al., 2013). Whole genome data has also revealed population structure,

402 strong genomic divergence $(\sim 50 \%)$ and signals of introgression in the human pathogens

403 Coccidioides immitis and C. posadasii (Neafsey et al., 2010). Comparing to these studies,

404 Suillus brevipes is an example of a much more recent population split, as demonstrated 
405 by the very low amount of reciprocally fixed alleles (0.01\%), low Dxy and low overall 406 Fst.

407 This study documents the first steps of fungal population differentiation, reporting 408 the most recent split between fungal populations to date. Our results corroborate the 409 existence of dispersal limitation in fungi and show positive selection associated with

410 abiotic factors as a driver for population differentiation in fungi, including a gene

411 involved in salt tolerance not previously hypothesized to be relevant in EM fungi. Further

412 functional tests can clarify the importance of this gene and shed light on the genetic basis

413 of adaptive traits in fungi. Furthermore, a broader geographic sampling, including

414 samples from other environments will aid in understanding the evolution of S. brevipes in 415 particular and of EM fungi in general.

417 Acknowledgements

418 We thank Holly Edes for technical assistance, the Computational Genomics Resource

419 Laboratory at the University of California, Berkeley for assistance with computational

420 analysis, Joey Spatafora and the 1000 Fungal Genomes Project for the Suillus brevipes

421 reference genome and annotation, Ben Wilson and Philipp Messer for sharing scripts to

422 perform selective sweep analysis, and Megan Phifer-Rixey for comments on an earlier

423 draft. Financial support was supported by National Science Foundation grant DBI

424 1046115. The work conducted by the U.S. Department of Energy Joint Genome Institute,

425 a DOE Office of Science User Facility, is supported under Contract No. DE-AC02-

426 05CH11231. 


\section{References}

Amend A, Garbelotto M, Fang Z et al. (2010) Isolation by landscape in populations of a prized edible mushroom Tricholoma matsutake. Conserv Genet, 11, 795-802.

Amend A, Seifert KA, Samson R et al. (2010) Indoor fungal composition is geographically patterned and more diverse in temperate zones than in the tropics. Proc Natl Acad Sci, 107, 13748-13753.

Apse MP, Aharon GS et al. (1999) Salt tolerance conferred by overexpression of a vacuolar $\mathrm{Na}+/ \mathrm{H}+$ antiport in Arabidopsis. Science, 285, 1256-1258.

Bañuelos MA, Sychrová H, Bleykasten-Grosshans C et al. (1998) The Nha1 antiporter of Saccharomyces cerevisiae mediates sodium and potassium efflux. Microbiol Read Engl, 144, 2749-2758.

Barnett D, Garrison E, Quinlan A et al. (2011) BamTools: a C++ API and toolkit for analyzing and managing BAM files. Bioinformatics, 17, 1691-1692.

Benjamini Y, Hochberg Y (1995) Controlling the False Discovery Rate: A Practical and Powerful Approach to Multiple Testing. J R Stat Soc Ser B Methodol, 57, 289300.

Bergemann SE, Douhan GW, Garbelotto M et al. (2006) No evidence of population structure across three isolated subpopulations of Russula brevipes in an oak/pine woodland. New Phytol, 170, 177-184.

Bergemann SE, Miller SL (2002) Size, distribution, and persistence of genets in local populations of the late-stage ectomycorrhizal basidiomycete, Russula brevipes. New Phytol, 156, 313-320.

Brown AMV, Huynh LY, Bolender CM et al. (2013) Population genomics of a symbiont in the early stages of a pest invasion. Mol Ecol, 23, 1516-1530.

Caicedo AL, Williamson SH, Hernandez RD et al. (2007) Genome-Wide Patterns of Nucleotide Polymorphism in Domesticated Rice. PLoS Genet, 3, e163.

Carriconde F, Gryta H, Jargeat P et al. 2008. High sexual reproduction and limited contemporary dispersal in the ectomycorrhizal fungus Tricholoma scalpturatum: new insights from population genetics and spatial autocorrelation analysis. $\mathrm{Mol}$ Ecol, 17, 4433-4445.

Cruickshank TE, Hahn MW (2014) Reanalysis suggests that genomic islands of speciation are due to reduced diversity, not reduced gene flow. Mol Ecol, 23, 3133-3157.

Dahlberg A, Stenlid J (1994) Size, distribution and biomass of genets in populations of Suillus bovinus (L.: Fr.) Roussel revealed by somatic incompatibility. New Phytol, 128, 225-234.

Danecek P, Auton A, Abecasis G et al. (2011) The variant call format and VCFtools. Bioinformatics, 27, 2156-2158.

Douhan GW, Vincenot L, Gryta H et al. (2011) Population genetics of ectomycorrhizal fungi: from current knowledge to emerging directions. Fungal Biol, 115, 569597.

Dunham SM, Mujic AB, Spatafora JW et al. (2013) Within-population genetic structure differs between two sympatric sister-species of ectomycorrhizal fungi, Rhizopogon vinicolor and $R$. vesiculosus. Mycologia, 105, 814-826. 
472

473

474

475

476

477

478

479

480

481

482

483

484

485

486

487

488

489

490

491

492

493

494

495

496

497

498

499

500

501

502

503

504

505

506

507

508

509

510

511

512

513

514

515

516
Ellison CE, Hall C, Kowbel D et al. (2011) Population genomics and local adaptation in wild isolates of a model microbial eukaryote. Proc Natl Acad Sci, 108, 28312836.

Felsenstein, J (2002) \{PHYLIP\} (Phylogeny Inference Package) version 3.6a3.

Frenkel O, Peever TL, Chilvers MI et al. (2010) Ecological Genetic Divergence of the Fungal Pathogen Didymella rabiei on Sympatric Wild and Domesticated Cicer spp. (Chickpea). Appl Environ Microbiol, 76, 30-39.

Gladieux P, Ropars J, Badouin H et al. (2014) Fungal evolutionary genomics provides insight into the mechanisms of adaptive divergence in eukaryotes. Mol Ecol, 23, 753-773.

Gnerre S, MacCallum I, Przybylski D et al. (2011) High-quality draft assemblies of mammalian genomes from massively parallel sequence data. Proc Natl Acad Sci, 108, 1513-1518.

Green J, Bohannan BJM (2006) Spatial scaling of microbial biodiversity. Trends Ecol Evol, 21, 501-507.

Grigoriev IV, Nikitin R, Haridas S et al. (2013) MycoCosm portal: gearing up for 1000 fungal genomes. Nucleic Acids Res, 42, D699-D704.

Grubisha LC, Bergemann SE, Bruns TD. 2007. Host islands within the California Northern Channel Islands create fine-scale genetic structure in two sympatric species of the symbiotic ectomycorrhizal fungus Rhizopogon. Mol Ecol, 16, $1811-1822$.

Gutenkunst RN, Hernandez RD, Williamson SH et al. (2009) Inferring the Joint Demographic History of Multiple Populations from Multidimensional SNP Frequency Data. PLoS Genet, 5, e1000695.

James TY, Kauff F, Schoch CL et al. (2006) Reconstructing the early evolution of Fungi using a six-gene phylogeny. Nature, 443, 818-822.

Kretzer AM, Dunham S, Molina R et al. (2005) Patterns of vegetative growth and gene flow in Rhizopogon vinicolor and $R$. vesiculosus (Boletales, Basidiomycota). Mol Ecol, 14, 2259-2268.

Kuo A, Bushnell B, Grigoriev IV (2014) Fungal genomics: sequencing and annotation. In: Martin F, editor. Fungi. Advances in Botanical Research, 70, Elsevier, 1-52.

Langmead B, Salzberg SL (2012) Fast gapped-read alignment with Bowtie 2. Nat Methods, 9, 357-359.

Li H, Handsaker B, Wysoker A et al. (2009) The Sequence Alignment/Map format and SAMtools. Bioinforma Oxf Engl, 25, 2078-2079.

Liti G, Carter DM, Moses AM et al. (2009) Population genomics of domestic and wild yeasts. Nature, 458, 337-341.

Mboup M, Bahri B, Leconte M et al. (2012) Genetic structure and local adaptation of European wheat yellow rust populations: the role of temperature-specific adaptation. Evol Appl, 5, 341-352.

McDonald JH, Kreitman M (1991) Adaptive protein evolution at the Adh locus in Drosophila. Nature, 351, 652-654.

McKenna A, Hanna M, Banks E et al. (2010) The Genome Analysis Toolkit: a MapReduce framework for analyzing next-generation DNA sequencing data. Genome Res, 20, 1297-1303. 
Mita SD, Siol M (2012) EggLib: processing, analysis and simulation tools for population genetics and genomics. BMC Genet, 13, 27. populations in heavy metal polluted and nonpolluted habitats. Mol Ecol, 16, $4728-4737$.

Nass R, Cunningham KW, Rao R (1997) Intracellular sequestration of sodium by a novel $\mathrm{Na}+/ \mathrm{H}+$ exchanger in yeast is enhanced by mutations in the plasma membrane H+-ATPase. J Biol Chem, 272, 26145-26152.

Neafsey DE, Barker BM, Sharpton TJ et al. (2010) Population genomic sequencing of Coccidioides fungi reveals recent hybridization and transposon control. Genome Res, 20, 938-946.

Noor MAF, Bennett SM (2009) Islands of speciation or mirages in the desert? Examining the role of restricted recombination in maintaining species. Heredity, 103, 439444.

Peay KG, Garbelotto M, Bruns TD (2010) Evidence of dispersal limitation in soil microorganisms: Isolation reduces species richness on mycorrhizal tree islands. Ecology, 91, 3631-3640.

Peay KG, Schubert MG, Nguyen NH et al. (2012) Measuring ectomycorrhizal fungal dispersal: macroecological patterns driven by microscopic propagules. Mol Ecol, 21, 4122-4136.

Rivera Y, Burchhardt KM, Kretzer AM (2014) Little to no genetic structure in the ectomycorrhizal basidiomycete Suillus spraguei (Syn. S. pictus) across parts of the northeastern USA. Mycorrhiza, 24, 227-232.

Rosenblum EB, James TY, Zamudio KR et al. (2013) Complex history of the amphibiankilling chytrid fungus revealed with genome resequencing data. Proc Natl Acad Sci, 110, 9385-9390.

Roy M, Dubois M-P, Proffit M et al. (2008) Evidence from population genetics that the ectomycorrhizal basidiomycete Laccaria amethystina is an actual multihost symbiont. Mol Ecol, 17, 2825-2838.

Schechter S, Branco S (2014) The Ecology and Evolution of Mycorrhizal Fungi in Extreme Soils. In: Rajakaruna N, Boyd R, Harris T (eds). Plant Ecology and Evolution in Harsh Environments. Nova Publishers.

Smith AH, Thiers HD (1964) A contribution towards a monograph of North American species of Suillus. Published by the authors, Ann Harbor, MI.

Smith SE, Read DJ (2010) Mycorrhizal Symbiosis. Academic Press.

Talbot JM, Bruns TD, Taylor, JW et al. (2014) Endemism and functional convergence across the North American soil mycobiome. Proc Natl Acad Sci, 111, 6341-6346.

Tang H, Peng J, Wang P et al. (2005) Estimation of individual admixture: Analytical and study design considerations. Genet Epidemiol, 28, 289-301.

Taylor JW, Turner E, Townsend JP et al. (2006) Eukaryotic microbes, species recognition and the geographic limits of species: examples from the kingdom Fungi. Philos Trans R Soc B Biol Sci, 361, 1947-1963.

Vacher C, Vile D, Helion E et al. (2008) Distribution of parasitic fungal species richness: influence of climate versus host species diversity. Divers Distrib, 14, 786-798.

Zeng K, Fu Y-X, Shi S et al. (2006) Statistical Tests for Detecting Positive Selection by Utilizing High-Frequency Variants. Genetics, 174, 1431-1439. 
563

564

565

566

567

568

569

570

571

572

573

574

575
Zhou Z, Miwa M, Hogetsu T (2001) Polymorphism of simple sequence repeats reveals gene flow within and between ectomycorrhizal Suillus grevillei populations. New Phytol, 149, 339-348.

\section{Figures and figure legends:}

A

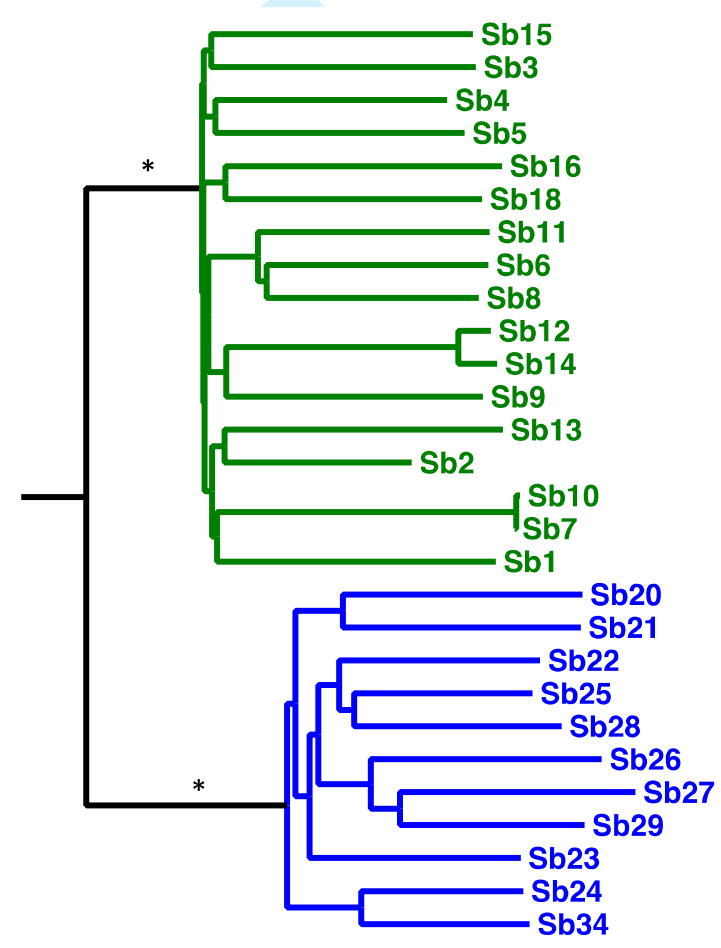

B

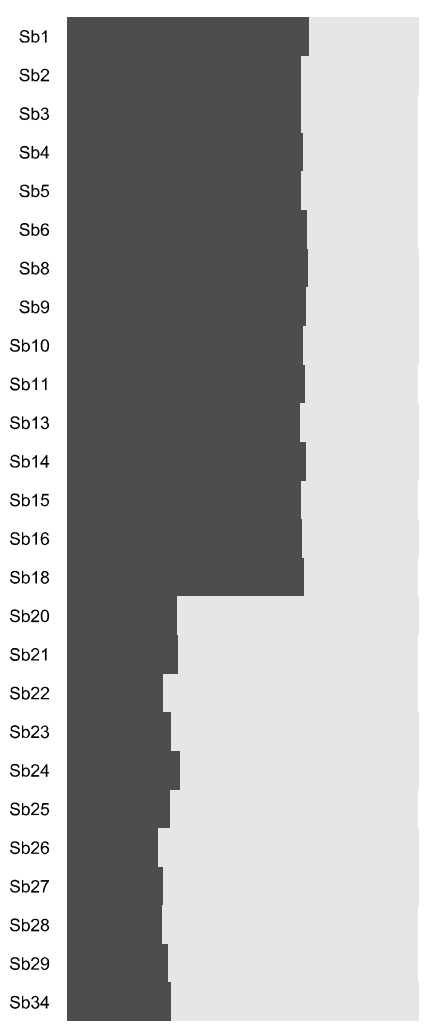

Figure 1 - Evidence for population structure between the coastal and montane Suillus brevipes populations. a) Neighbor-joining tree based on 567192 SNPs after singleton exclusion; green branches depict individuals from the mountains (Yosemite National Park, CA) and blue branches refer to coastal individuals ( $\mathrm{Sb} 20$ was collected from $\mathrm{Pt}$ Reyes, Sb21 from Salt Point, and all others from Mendocino Co, CA); Sb7 and Sb10 are clones. * indicates bootstrap support values of 100. b) FRAPPE diagrams showing genetic differentiation between coastal and montane individuals. 


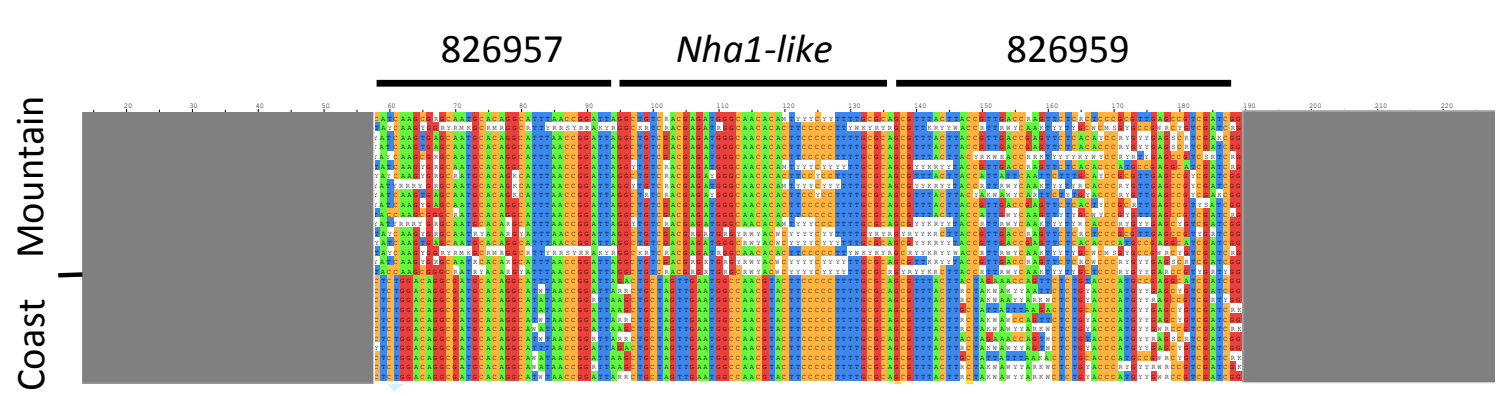

Figure 2-Genomic regions of divergence genotype matrices. Columns depict heterozygous sites. The location of introns is not shown. Individuals are grouped by population of origin (coast and mountain). The matrix shows three adjacent genes including $20 \%$ of genic reciprocally fixed SNPs in scaffold 12.826959 codes for a cysteine-type endopeptidase, Nhal-like (826958) for a $\mathrm{Na}^{+} / \mathrm{H}^{+}$exchanger, and 826957 has an unknown function. These three genes are both Dxy and Fst outliers (see text for 603 details).

608

609

610

611

612

613

614

615

616

617

618 


\section{Tables}

Table 1 - Genomic summary statistics for the montane and coastal Suillus brevipes populations with number of segregating sites, nucleotide diversity $(\pi), \pi$ for silent sites, Tajima's D, and Zeng's E for 5Kb genomic windows and genes.

\begin{tabular}{lcccc} 
& $\begin{array}{c}\text { Mountain (5kb } \\
\text { windows) }\end{array}$ & $\begin{array}{c}\text { Mountain } \\
\text { (genes) }\end{array}$ & $\begin{array}{c}\text { Coast (5kb } \\
\text { windows) }\end{array}$ & $\begin{array}{c}\text { Coast } \\
\text { (genes) }\end{array}$ \\
\hline Segregating & 52.2 & 10.7 & 48.8 & 12.7 \\
sites & $2.7 \times 10^{-3}$ & $2.1 \times 10^{-3}$ & $3.2 \times 10^{-3}$ & $2.0 \times 10^{-3}$ \\
$\boldsymbol{\pi}$ & - & $5.3 \times 10^{-3}$ & - & $5.0 \times 10^{-3}$ \\
$\boldsymbol{\pi}$ Silent & - & $1.2 \times 10^{-3}$ & - & $1.1 \times 10^{-3}$ \\
$\boldsymbol{\pi}$ non-Silent & -0.15 & 0.31 & -0.4 & 0.36 \\
Tajima's D & - & -2.01 & - & -1.94 \\
Zeng's E & & & &
\end{tabular}

638 Table 3 - Optimized log-likelihoods for demographic models as provided by $\partial \mathrm{a} \partial \mathrm{i}$ (using

639 the unfolded site frequency spectra). Tested models included isolation, migration, 640 migration and exponential growth, migration with two epochs, and migration with two 641 epochs and exponential growth. The isolation model is the most likely model and is 642 highlighted in bold.

643

\begin{tabular}{lcc} 
Model & $\begin{array}{c}\text { Optimized log- } \\
\text { likelihood }\end{array}$ & Theta \\
\hline Isolation & $\mathbf{- 3 2 5 9 5 . 1}$ & $\mathbf{1 3 5 1 3 7 . 6}$
\end{tabular}




$\begin{array}{lcc}\text { Migration } & -76454.7 & 112079.5 \\ \text { Migration/Exponential } & -62192.6 & 17137.5 \\ \text { Migration 2 epochs } & -141888.1 & 20751.7 \\ \text { Migration 2 epochs/ } & -117173.2 & 21888.5 \\ \text { Exponential } & & \end{array}$

644

645

646

647

648

649

650

651

652 Table $5-1 \mathrm{~kb}$ window Fst gene $0.1 \%$ outliers, with localization in genome and protein

653 function (with respective description) if available.

654

\section{No Migration model}

\begin{tabular}{lccc}
\cline { 2 - 4 } \multicolumn{1}{c}{ Parameter } & Estimate & Mean & SD \\
\hline Ancestral $\mathrm{Ne}$ & $6.53 \times 10^{5}$ & $4.1 \times 10^{5}$ & 608.1 \\
Mountain $\mathrm{Ne}$ after split & $3.87 \times 10^{5}$ & $2.3 \times 10^{5}$ & 3824.1 \\
Coast $\mathrm{Ne}$ after split & $1.16 \times 10^{5}$ & $7.3 \times 10^{4}$ & 1353.9 \\
Divergence time & $2.5 \times 10^{4}$ & $1.6 \times 10^{4}$ & 291.5
\end{tabular}

Table 4 - Maximum-likelihood demographic parameter estimates for the isolation model to the joint allele frequency spectrum for the mountain and coastal $S$. brevipes

populations, with respective means and standard deviation (SD). $\mu=10-9$; divergence time in generations.

\begin{tabular}{|c|c|c|c|c|}
\hline Scaffold & $\begin{array}{l}\text { Protein } \\
\text { ID }\end{array}$ & Function & Description & Obs \\
\hline 2 & 763737 & $\begin{array}{c}\text { Translation elongation } \\
\text { factor }\end{array}$ & & \\
\hline 2 & 948321 & $\begin{array}{l}\text { Proton-transporting } \\
\text { ATPase activity, } \\
\text { rotational mechanism }\end{array}$ & & \\
\hline 4 & 713130 & Transporter activity & $\begin{array}{l}\text { MFS general substrate } \\
\text { transporter }\end{array}$ & \\
\hline 8 & 814720 & $\begin{array}{l}\text { Purine ribonucleoside } \\
\text { monophosphate } \\
\text { biosynthetic process }\end{array}$ & $\begin{array}{c}\text { Adenosine/AMP } \\
\text { deaminase }\end{array}$ & \\
\hline 8 & 853122 & GTPase activity & $\begin{array}{c}\text { Translation elongation } \\
\text { factor EFG/EF2, C- } \\
\text { terminal }\end{array}$ & \\
\hline 8 & 814728 & Catalytic activity & $\begin{array}{c}\text { Alcohol dehydrogenase, } \\
\text { zinc-binding }\end{array}$ & \\
\hline 9 & 860915 & $\begin{array}{l}\text { Sequence-specific } \\
\text { DNA binding } \\
\text { transcription factor } \\
\text { activity }\end{array}$ & $\begin{array}{l}\text { Zinc finger, GATA- } \\
\text { type }\end{array}$ & \\
\hline
\end{tabular}




\begin{tabular}{|c|c|c|c|c|}
\hline 12 & 826957 & - & & $\begin{array}{l}\text { Dxy outlier; } \\
\text { gene with } \\
\text { fixed } \\
\text { differences }\end{array}$ \\
\hline 12 & 826958 & $\begin{array}{l}\text { Regulation of } \mathrm{pH}, \\
\text { solute:hydrogen } \\
\text { antiporter }\end{array}$ & $\begin{array}{l}\text { Sodium/hydrogen } \\
\text { exchanger }\end{array}$ & $\begin{array}{l}\text { Dxy outlier; } \\
\text { gene with } \\
\text { fixed } \\
\text { differences }\end{array}$ \\
\hline 12 & 826959 & $\begin{array}{l}\text { Cysteine-type } \\
\text { endopeptidase }\end{array}$ & $\begin{array}{l}\text { Peptidase C1B, } \\
\text { bleomycin hydrolase }\end{array}$ & $\begin{array}{l}\text { Dxy outlier; } \\
\text { gene with } \\
\text { fixed } \\
\text { differences }\end{array}$ \\
\hline 14 & 718701 & $\begin{array}{c}\text { Glucose-6-phosphate } \\
\text { dehydrogenase }\end{array}$ & & \\
\hline 16 & 795305 & $\begin{array}{l}\text { Nucleotide binding, } \\
\text { nucleotide-excision } \\
\text { repair }\end{array}$ & & \\
\hline 22 & 862126 & $\begin{array}{l}\text { Oxidoreductase } \\
\text { activity }\end{array}$ & $\begin{array}{l}\text { Pyridine nucleotide- } \\
\text { disulphide } \\
\text { oxidoreductase, class I }\end{array}$ & \\
\hline 32 & 830321 & tRNA processing & & \\
\hline 32 & 830324 & $\begin{array}{l}\text { Oxidoreductase } \\
\text { activity }\end{array}$ & Aldo/keto reductase & \\
\hline 41 & 831287 & Catalytic activity & $\begin{array}{c}\text { Phospholipase } \\
\text { D/Transphosphatidylase }\end{array}$ & \\
\hline 41 & 855962 & $\begin{array}{c}\text { Protein modification } \\
\text { process }\end{array}$ & Ubiquitin & \\
\hline 42 & 831382 & Catalytic activity & $\begin{array}{c}\text { Serralysin-like } \\
\text { metalloprotease, C- } \\
\text { terminal }\end{array}$ & \\
\hline 63 & 733034 & Transporter activity & $\begin{array}{l}\text { MFS general substrate } \\
\text { transporter }\end{array}$ & \\
\hline 66 & 804723 & $\begin{array}{l}\text { L-serine ammonia- } \\
\text { lyase activity }\end{array}$ & $\begin{array}{l}\text { Iron-sulphur-dependent } \\
\text { L-serine dehydratase } \\
\text { single chain form }\end{array}$ & Dxy outlier \\
\hline 66 & 779351 & $\begin{array}{l}\text { DNA ligase }(\mathrm{ATP}) \\
\text { activity, DNA } \\
\text { replication, DNA } \\
\text { repair }\end{array}$ & & \\
\hline 66 & 733526 & $\begin{array}{l}\text { Nucleic acid binding, } \\
\text { zinc ion binding }\end{array}$ & & \\
\hline 85 & 834749 & $\begin{array}{l}\text { Two-component } \\
\text { response regulator } \\
\text { activity }\end{array}$ & & \\
\hline
\end{tabular}




$$
\begin{array}{lll}
\text { 123 } & 783492 & \begin{array}{l}
\text { Transferase activity } \\
\text { nitrogenous groups }
\end{array}
\end{array}
$$

655

656

657

658

659

660

661

662

663

664

665

666

667

668

669

670

671

672

673

674

675

676

677

678

679

680

681

682

683

684

685

686

687

688

689

690

691

692

693

694

695

696

697

\section{Data Accessibility}

DNA sequences : Short Read Archive accessions in table S1

Suillus brevipes reference genome and annotation:

http://genome.jgi.doe.gov/Suillus_brevipes/

$S$. brevipes raw single nucleotide polymorphism list : Dryad doi XXXXX

$S$. brevipes neighbor-joining tree : Dryad doi XXXXX

\section{Author Contributions}

SB, TDB and JWT designed the study and collected samples. SB, PG and CEE performed analyses. AK, KL, AL and IVG assembled and annotated the Suillus brevipes reference genome. SB, PG, CEE, H-L L, RV, KGP, JWT and TDB wrote the paper.

\section{Supporting Information}

Table S1 - Suillus brevipes isolate location, habitat, pine host, coordinates and elevation, number of raw and high quality reads, $\%$ alignment rate, genome coverage, and Short Read Archive accession numbers. * Sb2 was the isolate used to generate the reference genome for the species (http://genome.jgi-psf.org/Suibr1/Suibr1.home.html). See text for details.

Table S2 - 5kb window Dxy gene 1\% outliers, with localization in genome and protein function and description. Genes in scaffold 12 include $20 \%$ of the reciprocally fixed differences falling in genic regions and gene 828720 was found to under positive selection by McDonald Kreitman test.

Table S3 - Genes under positive selection as inferred by McDonald-Kreitman tests on genes using $S$. luteus as the outgroup. $P$ values were adjusted using the BenjaminiHochberg correction.

Table S4 - Selective sweep analysis; top five $\mathrm{H}$ value peaks for coastal and mountain Suillus brevipes populations.

Figure S1 - Observed and estimated site frequency spectra under the isolation model from coastal and montane Suillus brevipes populations. 